Polymer Journal, Vol. 39, No. 9, pp. 968-974 (2007)

(C) 2007 The Society of Polymer Science, Japan

\title{
Synthesis and Properties of Substituted Polyacetylenes Having Cyclohexyl Groups
}

\author{
Yanming Hu, Masashi Shiotsuki, Fumio SANDA, and Toshio MASUdA ${ }^{\dagger}$ \\ Department of Polymer Chemistry, Graduate School of Engineering, Kyoto University, \\ Katsura Campus, Nishikyo-ku, Kyoto 615-8510, Japan
}

(Received April 25, 2007; Accepted June 20, 2007; Published July 31, 2007)

\begin{abstract}
Disubstituted acetylenes containing cyclohexyl groups $\left(\mathrm{RC} \mathrm{CC}_{6} \mathrm{H}_{4}-p-c y c l o-\mathrm{C}_{6} \mathrm{H}_{11}, \mathrm{R}=\mathrm{Ph}, p\right.$ $\mathrm{Me}_{3} \mathrm{SiPh}$, p-tert-BuMe $\mathrm{S}_{2} \mathrm{SiOPh}, \mathrm{Me}, \mathrm{Cl}, \mathbf{1 a}-\mathbf{e}$, respectively) were polymerized with Ta- or Mo-based catalyst, and 1a, 1c, and 1e provided high molecular weight polymers. Free-standing membranes of poly(1a) and poly $(\mathbf{1 c})$ were fabricated from toluene solution. Hydroxy-containing membrane poly(2c) was prepared by desilylation of siloxy-containing poly(1c) using trifluroacetic acid. According to thermogravimetric analysis (TGA), the produced polymers exhibited high thermal stability, and the onset temperatures of weight loss in air were $\sim 340^{\circ} \mathrm{C}$. The oxygen permeability coefficients of these membranes were in the range of 17-230 barrers. The point of poly(2c) in the $P_{\mathrm{CO}_{2}}$ vs. $P_{\mathrm{CO}_{2}} / P_{\mathrm{CH}_{4}}$ plot were located above Robeson's upper bound. [doi:10.1295/polymj.PJ2007021]

KEY WORDS Substituted Polyacetylene / Membrane / Gas Permeability /
\end{abstract}

Polyacetylenes are attractive polymers for potential applications as functional materials in optoelectronics, stimuli-responsive materials, gas separation materials, etc. ${ }^{1-8}$ A variety of substituted polyacetylenes have been synthesized using metal carbene and metal halide catalysts. Key advantages of substituted polyacetylenes compared to polyacetylene are their stability and solubility. Among them, some substituted polyacetylenes, especially polymers from disubstituted polyacetylenes exhibit high gas permeability due to the rigid main chain composed of alternating double bonds and the steric repulsion of spherical pendent groups. For instance, poly[1-(trimethylsilyl)-1-propyne] [poly(TMSP)] displays the highest gas permeability among all the existing polymers. ${ }^{9,10}$ Poly[1-phenyl-2-( $p$-trimethylsilyl)phenylacetylene] [poly(TMSDPA)] exhibits both high gas permeability and thermal stability; its oxygen permeability coefficient $\left(P_{\mathrm{O}_{2}}\right)$ is as large as 1100 barrers, and the onset temperature of weight loss is $420^{\circ} \mathrm{C}$. $^{11,12}$

Recently, the study of gas permeability and permselectivity of polymeric membranes has become a subject of substantial interest in both industrial and academic laboratories. The main motivation for these studies is primarily an empirical search for improved materials as gas separation membranes. Another aim is the development of rules for prediction of the permeation properties. To find such rules, it is necessary to have deep understanding of the structures of the polymers and their gas transport behavior. As a bulky group, cyclohexyl has the inherent flexibility due to its possible conformational changes. The cyclohexyl moiety has been introduced into the main chain or side chain of various types of gas separation membrane materials, such as polynorbornenes, ${ }^{13}$ polyimides, ${ }^{14}$ and polysiloxanes. ${ }^{15}$ Although there are a few reports about polyacetylenes having cyclohexyl moieties, their works has focused on the optical properties of the polymers. ${ }^{16,17}$ The effect of incorporation of cyclohexyl groups into polyacetylenes on the gas permeability has not been studied.

The present study deals with the polymerization of various disubstituted acetylenes containing cyclohexyl groups (1a-1e), and fabrication of free-standing membranes from the resultant polymers $[\operatorname{poly}(\mathbf{1 a})$ and poly(1c)] (Scheme 1). We further prepared a desilylated polymer membrane [poly(2c)], and examined the general properties and gas permeability of the polymer membranes.

\section{EXPERIMENTAL}

\section{General}

Molecular weights of polymers were estimated by gel permeation chromatography $\left(\mathrm{CHCl}_{3}\right.$ as eluent, polystyrene calibration). IR spectra were recorded on a JASCO FT/IR-4100 spectrophotometer. NMR spectra were observed on a JEOL EX-400 spectrometer. Elemental analysis of monomers was carried out at the Microanalytical Center of Kyoto University. Thermogravimetric analysis (TGA) was conducted in air with a Perkin-Elmer TGA7 thermal analyzer. Gas permeability coefficients of polymer membranes were measured with a Rikaseiki K-315-N gas permeability apparatus at $25^{\circ} \mathrm{C}$.

${ }^{\dagger}$ To whom correspondence should be addressed (Tel: +81-75-383-2589, Fax: +81-75-383-2590, E-mail: masuda@adv.polym.kyoto-u.ac.jp). 


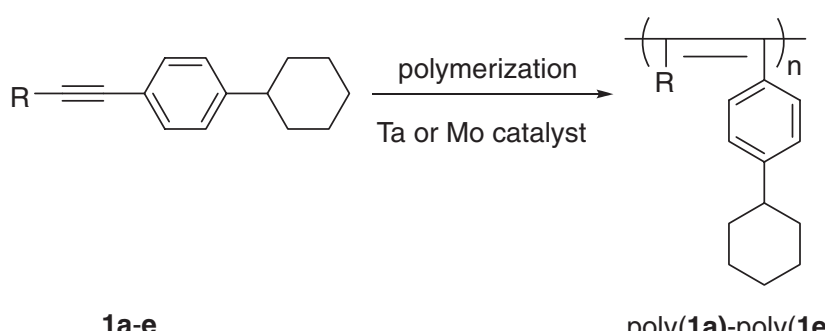

1a-e

poly(1a)-poly(1e)

$\mathrm{R}=\mathrm{Ph}(\mathbf{a}) ; p-\mathrm{Me}_{3} \mathrm{SiPh}(\mathbf{b}) ; p-t-\mathrm{BuMe}_{2} \mathrm{SiOPh}(\mathbf{c}) ; \mathrm{Me}(\mathbf{d}) ; \mathrm{Cl}(\mathbf{e})$

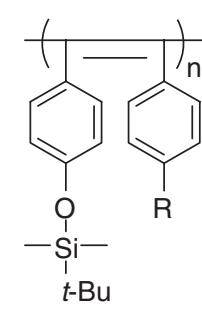

poly $(\mathbf{1 c}): R=$ cyclohexyl $\operatorname{poly}(1): \mathrm{R}=\mathrm{H}$
1) membrane fabrication

2) desilylation

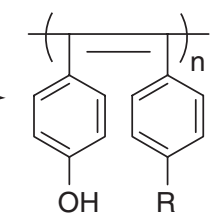

poly $(2 c): R=$ cyclohexyl poly (2): $\mathrm{R}=\mathrm{H}$
Scheme 1. Synthesis of substituted polyacetylenes.

\section{Materials}

$\mathrm{TaCl}_{5}$ (Strem Chemicals), $\quad \mathrm{MoCl}_{5}$ (Aldrich), $\mathrm{Mo}(\mathrm{CO})_{5}$ (Aldrich) as main catalyst components and $\mathrm{Ph}_{4} \mathrm{Sn}$ (Wako Pure Chemical) as a cocatalyst were used without further purification. $n-\mathrm{Bu}_{4} \mathrm{Sn}$ (Wako Pure Chemical) and $\mathrm{Et}_{3} \mathrm{SiH}$ as cocatalysts were used after distillation. Phenylcyclohexane (Wako Pure Chemical), tert-butyldimethylsilyl chloride (Aldrich), $p$-(trimethylsilyl)phenylacetylene (NOF), trifluoroacetic acid (TFA, Wako Pure Chemical Industries Ltd.), and common solvents were used without further purification except toluene and $\mathrm{CCl}_{4}$ as polymerization solvents. $p$-Cyclohexyliodobenzene ${ }^{18}$ and $p$-(tert-butyldimethylsiloxy)phenylacetylene ${ }^{19}$ were prepared according to the literature procedure. Monomers 1a-e were synthesized according to Scheme 2, referring to the literature concerning ethynylation and silylation..$^{20,21}$

\section{1-(p-Cyclohexyl)phenyl-2-phenylacetylene (1a)}

A $500 \mathrm{~mL}$ three-necked flask was equipped with a three-way stopcock and a magnetic stirring bar and was flushed with dry nitrogen. $p$-Cyclohexyliodobenzene $(18.0 \mathrm{~g}, 63 \mathrm{mmol})$, bis(triphenylphosphine)palladium dichloride ( $910 \mathrm{mg}, 1.3 \mathrm{mmol}$ ), cuprous iodide $(1.49 \mathrm{~g}, 7.8 \mathrm{mmol})$, triphenylphosphine $(1.36 \mathrm{~g}, 5.2$ $\mathrm{mmol})$, and triethylamine $(180 \mathrm{~mL})$ were placed in the flask. Then, phenylacetylene $(6.60 \mathrm{~g}, 65 \mathrm{mmol})$ in triethylamine $(20.0 \mathrm{~mL})$ solution was added, and the reaction mixture was stirred at room temperature overnight. After the triethylamine in the reaction mixture was evaporated, ether $(200 \mathrm{~mL})$ was added, and then insoluble salt formed was filtered off. The solution was washed with $1 \mathrm{M} \mathrm{HCl}$ aq. $(200 \mathrm{~mL})$ and then with water $(200 \mathrm{~mL} \times 3)$. The ethereal solution was dried over anhydrous sodium sulfate followed by rotary evaporation of ether. Purification of the crude product by flash column chromatography on silica gel (eluent: hexane) provided the desired product. Yield $38 \%$, white solid; $\mathrm{mp} 78.5-79.5^{\circ} \mathrm{C}$; IR $\left(\mathrm{KBr}, \mathrm{cm}^{-1}\right)$ : 2921, 2847, 1596, 1513, 1444, 1178, 1102, 910, 826, 754, 687, 523. ${ }^{1} \mathrm{H}$ NMR $\left(\mathrm{CDCl}_{3}, \mathrm{ppm}\right): 7.54-$ 7.39 (m, 4H, Ar), 7.38-7.26 (m, 3H, Ar), 7.21-7.14 (m, 2H, Ar), $2.50(\mathrm{~s}, 1 \mathrm{H}, \mathrm{Cy}), 1.85-1.40(\mathrm{~m}, 10 \mathrm{H}$, $\mathrm{Cy}) .{ }^{13} \mathrm{C}$ NMR $\left(\mathrm{CDCl}_{3}, \mathrm{ppm}\right): 148.4,131.5,128.2$, 128.0, 126.8, 123.4, 120.5, 89.6, 88.6, 44.5, 34.2, 26.8, 26.1. Anal. Calcd for $\mathrm{C}_{20} \mathrm{H}_{20}$ : C, 92.26; $\mathrm{H}$, 7.74. Found: C, $92.32 ; \mathrm{H}, 7.94$.

\section{1-(p-Trimethylsilylphenyl)-2-(p-cyclohexylphenyl)acet- ylene $(\mathbf{l b})$}

This monomer was prepared by the same method as for 1a using $p$-trimethylsilylphenylacetylene instead of phenylacetylene to give a white solid; yield $51 \%$, $\mathrm{mp} 147-148^{\circ} \mathrm{C}$. IR $\left(\mathrm{KBr}, \mathrm{cm}^{-1}\right): 2927,1593,1515$, 1447, 1250, 1100, 819, 756, 634, 531. ${ }^{1} \mathrm{H}$ NMR $\left(\mathrm{CDCl}_{3}, \mathrm{ppm}\right)$ : 7.51-7.44 (m, 6H, Ar), 7.24-7.17
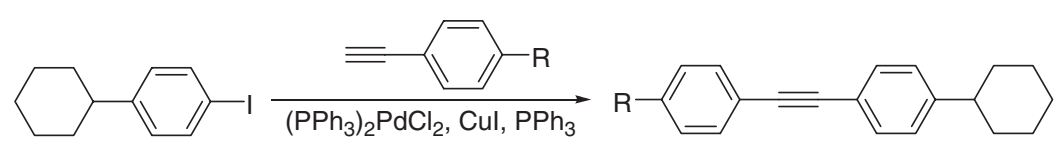

$\mathrm{R}=\mathrm{H}, \mathbf{1} \mathbf{a} ; \mathrm{Si}\left(\mathrm{CH}_{3}\right)_{3}, \quad \mathbf{1 b} ; \mathrm{OSi}\left(\mathrm{CH}_{3}\right)_{2} t-\mathrm{Bu}, \mathbf{1 c}$
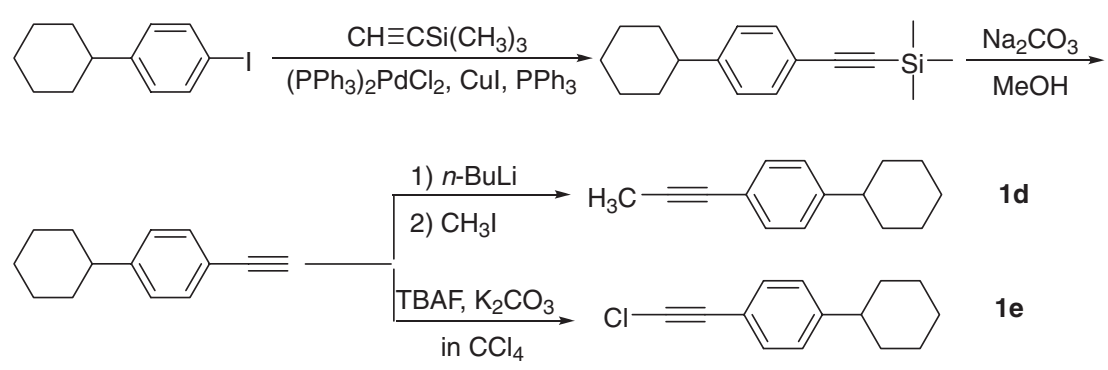

$1 d$

$1 e$

Scheme 2. Synthesis of substituted acetylene monomers containing a cyclohexyl group. 
(m, 2H, Ar), 2.50 (s, 1H, Cy), 1.85-1.40 (m, 10H, Cy). ${ }^{13} \mathrm{C}$ NMR $\left(\mathrm{CDCl}_{3}, \mathrm{ppm}\right): 148.5,140.7,133.2,131.6$, $130.6,126.9,123.8,120.6,90.0,88.8,44.5,34.2$, 26.8, 26.1, -1.2. Calcd for $\mathrm{C}_{23} \mathrm{H}_{28} \mathrm{Si}: \mathrm{C}, 83.07 ; \mathrm{H}$, 8.49. Found: C, $82.82 ; \mathrm{H}, 8.52$.

\section{1-(p-tert-Butyldimethylsiloxyphenyl)-2-(p-cyclohexyl- phenyl)acetylene (1c)}

This monomer was prepared by the same method as for 1a using p-tert-butyldimethylsiloxyphenylacetylene instead of phenylacetylene to give a white solid; yield $48 \%$, mp $90-91^{\circ} \mathrm{C}$. IR $\left(\mathrm{KBr}, \mathrm{cm}^{-1}\right)$ : 2927, 2853, 1599, 1518, 1254, 1165, 903, 846, 783, 542. ${ }^{1} \mathrm{H}$ NMR $\left(\mathrm{CDCl}_{3}, \mathrm{ppm}\right): 7.43-7.38$ (m, 4H, Ar), 7.16 (d, $J=$ $8.0 \mathrm{~Hz}, 2 \mathrm{H}, \mathrm{Ar}), 6.80(\mathrm{~d}, J=8.4 \mathrm{~Hz}, 2 \mathrm{H}, \mathrm{Ar}), 2.50(\mathrm{~s}$, $1 \mathrm{H}, \mathrm{Cy}), 1.85-1.40(\mathrm{~m}, 10 \mathrm{H}, \mathrm{Cy}) .{ }^{13} \mathrm{C} \mathrm{NMR}\left(\mathrm{CDCl}_{3}\right.$, ppm): $155.8,148.1,132.9,131.4,126.8,120.8,120.2$, 116.3, 88.6, 88.4, 44.5, 34.2, 26.8, 26.1, 25.6, 18.2, -4.4. Calcd for $\mathrm{C}_{26} \mathrm{H}_{34} \mathrm{OSi}$ C, 79.94; H, 8.77. Found: C, 79.73; H, 8.85.

\section{1-(p-Cyclohexylphenyl)-1-propyne (1d)}

A $100 \mathrm{~mL}$ three-necked flask was equipped with a three-way stopcock and a magnetic stirring bar. After the flask was flushed with dry nitrogen, a hexane solution of $n$-butyllithium $(14 \mathrm{~mL}, 1.58 \mathrm{~mol} / \mathrm{L}, 22 \mathrm{mmol})$ was placed in the flask at $-78^{\circ} \mathrm{C}$. A solution of $p$ cyclohexylphenylacetylene $(3.4 \mathrm{~g}, 18 \mathrm{mmol})$ in $\mathrm{THF}$ $(10 \mathrm{~mL})$ was added dropwise at $-78^{\circ} \mathrm{C}$, and the reaction mixture was left for $1 \mathrm{~h}$. Then a solution of meth$\mathrm{yl}$ iodide $(3.12 \mathrm{~g}, 22 \mathrm{mmol})$ in THF $(5 \mathrm{~mL})$ was added dropwise, and the reaction mixture was gradually warmed up to room temperature and was stirred for $24 \mathrm{~h}$. Then, a small amount of water was added under $0{ }^{\circ} \mathrm{C}$ with stirring. The solution was extracted with ether, and the organic phase was washed with $1 \mathrm{M}$ $\mathrm{HCl}$ aq. solution and water. The ethereal solution was dried over anhydrous sodium sulfate followed by rotary evaporation of ether. Purification of the crude product by flash column chromatography on silica gel (eluent: hexane) provided a white solid; yield $81 \%, \mathrm{mp} 35-36^{\circ} \mathrm{C}$. IR $\left(\mathrm{KBr}, \mathrm{cm}^{-1}\right)$ : 3448 , 3031, 2924, 2850, 1508, 1446, 1103, 999, 829, 551. ${ }^{1} \mathrm{H}$ NMR $\left(\mathrm{CDCl}_{3}, \mathrm{ppm}\right): 7.30(\mathrm{~d}, J=8.0 \mathrm{~Hz}, 2 \mathrm{H}$, Ar), $7.11(\mathrm{~d}, J=8.0 \mathrm{~Hz}, 2 \mathrm{H}, \mathrm{Ar}), 2.46(\mathrm{~s}, 1 \mathrm{H}, \mathrm{Cy})$, 2.03 (s, 3H, $\left.\mathrm{CH}_{3}\right), 1.85-1.40$ (m, 10H, Cy). ${ }^{13} \mathrm{C} \mathrm{NMR}$ $\left(\mathrm{CDCl}_{3}, \mathrm{ppm}\right)$ : 147.6, 131.4, 126.7, 121.3, 84.8, 79.8, 44.4, 34.3, 26.8, 26.1, 4.3. Calcd for $\mathrm{C}_{15} \mathrm{H}_{18}$ : C, 90.85; H, 9.15. Found: C, 90.63; H, 9.39.

\section{1-Chloro-2-(p-cyclohexylphenyl)acetylene (1e)}

A $100 \mathrm{~mL}$ flask was equipped with a three-way stopcock and a magnetic stirring bar. After the flask was flushed with dry nitrogen, $p$-cylohexylacetylene $(6.1 \mathrm{~g}, 33 \mathrm{mmol})$, potassium carbonate $(4.6 \mathrm{~g}, 33$ $\mathrm{mmol})$, and $\mathrm{CCl}_{4}(20 \mathrm{~mL})$ were fed in the flask. Then, a solution of tetra- $n$-butylammonium fluoride in THF $(3.3 \mathrm{~mL}, 1 \mathrm{~mol} / \mathrm{L}, 3.3 \mathrm{mmol})$ was added. After the resulting mixture was stirred for $2 \mathrm{~h}$ at room temperature, a small amount of methanol was added. The solution was washed with $1 \mathrm{M} \mathrm{HCl}$ aq. solution and then with water. The solution was dried over anhydrous sodium sulfate and then concentrated at reduced pressure. Purification of the crude product by flash column chromatography on silica gel (eluent: hexane) provided a white solid; yield $60 \%, \mathrm{mp} 66-67.5^{\circ} \mathrm{C}$. IR $\left(\mathrm{KBr}, \mathrm{cm}^{-1}\right): 2928,2851,1509,1447,1410,1104$, 1000, 891, 826, 546. ${ }^{1} \mathrm{H}$ NMR $\left(\mathrm{CDCl}_{3}, \mathrm{ppm}\right): 7.35$ (d, $J=8.0 \mathrm{~Hz}, 2 \mathrm{H}, \mathrm{Ar}), 7.14(\mathrm{~d}, J=8.0 \mathrm{~Hz}, 2 \mathrm{H}, \mathrm{Ar})$, 2.48 (s, 1H, Cy), 1.85-1.40 (m, 10H, Cy). ${ }^{13} \mathrm{C}$ NMR $\left(\mathrm{CDCl}_{3}, \mathrm{ppm}\right)$ : 148.8, 131.9, 126.9, 119.4, 69.5, 67.1, 44.5, 34.2, 26.8, 26.1. Calcd for $\mathrm{C}_{14} \mathrm{H}_{15} \mathrm{Cl}$ : C, 76.88; H, 6.91. Found: C, 76.61; H, 6.88.

\section{Polymerization}

Polymerizations were performed in a Schlenk tube equipped with a three-way stopcock under dry nitrogen. A detail procedure of polymerization is as follows: A monomer solution was prepared in a Schlenk tube by mixing monomer 1a $(65 \mathrm{mg})$ and toluene $(1.5 \mathrm{~mL})$. Another Schlenk tube was charged with $\mathrm{TaCl}_{5}$ (18 mg), $n$-Bu $\mathrm{Bu}_{4} \mathrm{Sn}(0.033 \mathrm{~mL})$, and toluene $(1.0 \mathrm{~mL})$; this catalyst solution was aged at $80^{\circ} \mathrm{C}$ for $10 \mathrm{~min}$. Then the monomer solution was added to the catalyst solution. Polymerization was carried out at $80^{\circ} \mathrm{C}$ for $24 \mathrm{~h}$, which was quenched with a small amount of methanol. The formed polymers were isolated by precipitation into a large amount of methanol, and dried to constant weight; the polymer yields were determined by gravimetry.

\section{Membrane Fabrication and Desilylation}

The membranes (thickness $c a$. 50-80 $\mu \mathrm{m}$ ) of polymers were fabricated by casting from toluene solution of the polymer (concentration $c a .0 .50-1.0 \mathrm{wt} \%$ ) onto a flat-bottomed Petri dish. Then, the dish was covered with a glass vessel for slow solvent evaporation ( $c a$. 4-7d). After membranes were prepared, they were immersed in methanol for $24 \mathrm{~h}$ and dried to constant weight at room temperature for $24 \mathrm{~h}$. With reference to the method described in the literature, ${ }^{22}$ the desilylation reaction of polymer membranes poly(1c) was carried out using TFA. A procedure of the desilylation reaction is as follows; a polymer membrane was immersed in a mixture of TFA and water (volume ratio $4: 1)$ at room temperature for $24 \mathrm{~h}$. The desilylated membrane was immersed in water for $24 \mathrm{~h}$, then washed with water to remove residual impurities, and dried to constant weight at room temperature for $24 \mathrm{~h}$. 
Density and Fractional Free Volume (FFV) of Polymer Membranes

The membrane density was determined by hydrostatic weighing using a Mettler Toledo balance (model AG204, Switzerland) and a density determination kit. ${ }^{23}$ In this method, a liquid with known density $\left(\rho_{0}\right)$ is needed, and the membrane density $(\rho)$ is given by the following equations:

$$
\rho=\rho_{0} M_{\mathrm{A}} /\left(M_{\mathrm{A}}-M_{\mathrm{L}}\right)
$$

where $M_{\mathrm{A}}$ is membrane weight in air, and $M_{\mathrm{L}}$ is membrane weight in the auxiliary liquid. Aqueous $\mathrm{NaNO}_{3}$ solution was used as the auxiliary liquid.

FFV $\left(\mathrm{cm}^{3}\right.$ of free volume $/ \mathrm{cm}^{3}$ of polymer) is commonly used to estimate the efficiency of chain packing and the amount of space (free volume) available for gas permeation in a polymer matrix. It is defined as $^{24,25}$

$$
\mathrm{FFV}=\left(v_{\mathrm{sp}}-v_{0}\right) / v_{\mathrm{sp}} \approx\left(v_{\mathrm{sp}}-1.3 v_{\mathrm{w}}\right) / v_{\mathrm{sp}}
$$

where $v_{\text {sp }}$ and $v_{0}$ are the specific volume and occupied volume (or zero-point volume at $0 \mathrm{~K}$ ) of the polymer, respectively. Typically, $v_{0}$ is 1.3 times as large as the van der Waals volume $\left(v_{\mathrm{w}}\right)$, which is calculated by the group contribution methods. ${ }^{26}$

\section{Measurement of Gas Permeabilities}

The gas permeability coefficients $(P)$ were calculated from the slopes of time-pressure curves in the steady state where the Fick's law holds. The gas diffusion coefficients $(D)$ were determined by the time lag method using the following equation:

$$
D=l^{2} / 6 \theta
$$

Here, $l$ is membrane thickness, and $\theta$ is time lag, which is given by the intercept of the asymptotic line of the time-pressure curve to the time axis. The membrane thickness was controlled so that the time lag would be in the range $10-300 \mathrm{~s}$, preferably 30 $150 \mathrm{~s}$. When the time lag was $<10 \mathrm{~s}$, the error of measurement became relatively large. If the time lag was, on the contrary, > $300 \mathrm{~s}$, the error based on baseline drift became serious. The gas solubility coefficients $(S)$ were calculated by using equation $S=P / D$.

\section{RESULTS AND DISCUSSION}

\section{Polymerization of Monomers $\mathbf{1 a}-\mathbf{1 d}$}

In general, the pentachlorides of group 5 transition metals $\mathrm{Ta}(\mathrm{V})$ and $\mathrm{Nb}(\mathrm{V})$ are effective as main catalysts for the polymerization of sterically crowded disubstituted acetylenes. Especially, the formation of high molecular weight poly(diarylacetylenes) is possible by use of mixed catalysts composed of $\mathrm{TaCl}_{5}$ and
Table I. Polymerization of monomers 1a-d by $\mathrm{TaCl}_{5}-n-\mathrm{Bu}_{4} \mathrm{Sn}$ catalyst ${ }^{\mathrm{a}}$

\begin{tabular}{cccccc}
\hline & & & \multicolumn{3}{c}{ Polymer $^{\mathrm{b}}$} \\
\cline { 3 - 6 } Run & Monomer & $\begin{array}{c}\mathrm{M}]_{0} \\
(\mathrm{~mol} / \mathrm{L})\end{array}$ & $\begin{array}{c}\text { Yield } \\
(\%)\end{array}$ & $M_{\mathrm{w}} \times 10^{-3 \mathrm{c}}$ & $M_{\mathrm{w}} / M_{\mathrm{n}}{ }^{\mathrm{c}}$ \\
\hline 1 & $\mathbf{1 a}$ & 0.10 & 81 & 4,100 & 1.5 \\
2 & $\mathbf{1 b}$ & 0.10 & 78 & $-^{\mathrm{d}}$ & - $^{\mathrm{d}}$ \\
3 & $\mathbf{1 c}$ & 0.10 & 30 & 2,100 & 5.3 \\
4 & $\mathbf{1 c}$ & 0.50 & 34 & 4,500 & 4.8 \\
5 & $\mathbf{1 d}$ & 0.10 & 5 & $\mathbf{-}^{\mathrm{d}}$ & - $^{\mathrm{d}}$ \\
6 & $\mathbf{1 d}$ & 1.0 & 71 & - $^{\mathrm{d}}$ & - $^{\mathrm{d}}$ \\
\hline
\end{tabular}

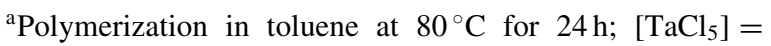
$20 \mathrm{mM}, \quad\left[n-\mathrm{Bu}_{4} \mathrm{Sn}\right]=40 \mathrm{mM}$. ${ }^{\mathrm{b}}$ Methanol-insoluble product. ${ }^{\mathrm{c}}$ Measured by GPC. ${ }^{\mathrm{d}}$ Insoluble in any solvents.

\begin{tabular}{|c|c|c|c|c|}
\hline \multirow[b]{2}{*}{ Run } & \multirow[b]{2}{*}{ Catalyst } & \multicolumn{3}{|c|}{ Polymer $^{\mathrm{b}}$} \\
\hline & & $\begin{array}{c}\text { Yield } \\
(\%)\end{array}$ & $M_{\mathrm{w}} \times 10^{-3 \mathrm{c}}$ & $M_{\mathrm{w}} / M_{\mathrm{n}}{ }^{\mathrm{c}}$ \\
\hline 1 & $\mathrm{MoCl}_{5}-n-\mathrm{Bu}_{4} \mathrm{Sn}$ & 87 & 270 & 3.8 \\
\hline 2 & $\mathrm{MoCl}_{5}-\mathrm{Ph}_{4} \mathrm{Sn}$ & 63 & 260 & 4.6 \\
\hline 3 & $\mathrm{MoCl}_{5}-\mathrm{Et}_{3} \mathrm{SiH}$ & 88 & 510 & 4.8 \\
\hline 4 & $\mathrm{Mo}(\mathrm{CO})_{5}-\mathrm{CCl}_{4}-h v^{\mathrm{d}}$ & 61 & 560 & 3.3 \\
\hline
\end{tabular}

Table II. Polymerization of monomer 1e by Mo-based catalysts ${ }^{\mathrm{a}}$

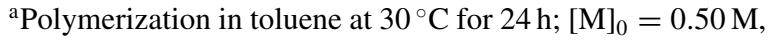
$[\mathrm{Mo}]=20 \mathrm{mM}$, [Cocat $]=40 \mathrm{mM} .{ }^{\mathrm{b}}$ Methanol-insoluble product. ${ }^{\mathrm{c}}$ Measured by GPC. ${ }^{\mathrm{d}}$ Polymerization in $\mathrm{CCl}_{4}$ at $30^{\circ} \mathrm{C}$ for $24 \mathrm{~h} ;[\mathrm{M}]_{0}=1.0 \mathrm{M},\left[\mathrm{Mo}(\mathrm{CO})_{5}\right]=10 \mathrm{mM}$.

suitable organometallic cocatalysts..$^{27,28}$ Table I shows the results of the polymerization of monomers 1a-1d by using $\mathrm{TaCl}_{5}-n-\mathrm{Bu}_{4} \mathrm{Sn}$ catalyst. Monomer 1a afforded a polymer with a high molecular weight $\left(M_{\mathrm{w}}=4,100 \times 10^{3}\right)$ in a good yield $(81 \%)$. The polymerization of 1c also gave a polymer having a high molecular weight but in a low polymer yield $(\sim 30 \%)$ even at a high monomer concentration $\left([\mathrm{M}]_{0}=0.50 \mathrm{M}\right)$. These two polymers were completely soluble in common organic solvents such as toluene, chloroform, and THF. On the other hand, the polymerization of $\mathbf{1 b}$ and $\mathbf{1 d}$ afforded solvent-insoluble polymers. Thus the monomer structure significantly affected both polymerization behavior and polymer solubility.

\section{Polymerization of Monomer 1e}

Table II summarizes the results of polymerization of monomer 1e using various Mo-based catalysts, which are effective to the polymerization of chlorine-containing disubstituted acetylenes. ${ }^{29,30}$ With use of $\mathrm{MoCl}_{5}$-cocatalyst systems, monomer 1e afforded polymers with high molecular weights $\left(M_{\mathrm{w}}=270 \times\right.$ 


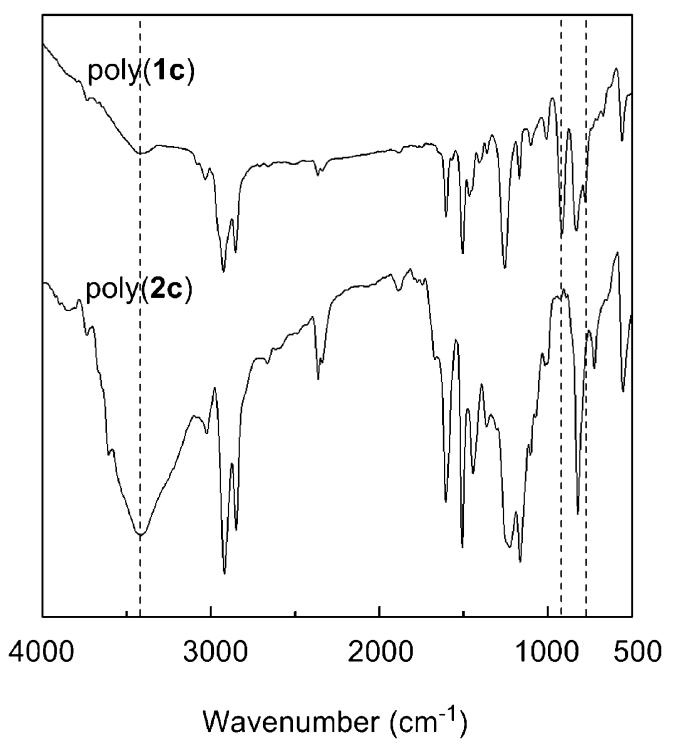

Figure 1. IR spectra of $\operatorname{poly}(\mathbf{1 c})$ and its desilylated product poly (2c) (KBr Pellet).

$\left.10^{3}-510 \times 10^{3}\right)$ in good yields $(63 \%-88 \%)$. $\mathrm{Mo}(\mathrm{CO})_{5}-\mathrm{CCl}_{4}-h v$ was also effective to this monomer, and the $M_{\mathrm{w}}$ of the polymer reached $560 \times 10^{3}$, which was the largest for this monomer.

\section{Fabrication and Desilylation of Poly(1c) Membrane}

Free-standing membranes could be prepared by casting from toluene solution of $\operatorname{poly}(\mathbf{1 a})$ and poly(1c). The formed membranes were sufficiently tough, uniform, and transparent. On the other hand, the membranes of poly $(\mathbf{1 b}), \operatorname{poly}(\mathbf{1 d})$, and $\operatorname{poly}(\mathbf{1 e})$ could not be prepared because of insolubility or brittleness.

Desilylation of poly $(\mathbf{1 c})$ membrane was carried out in a mixture of TFA $/ \mathrm{H}_{2} \mathrm{O}$ (4:1 volume ratio) at room temperature for $24 \mathrm{~h}$. The reaction proceeded to completion, which gave the corresponding hydroxy-containing poly $(\mathbf{2 c})$. The completion of desilylation was confirmed by IR spectroscopy (Figure 1). In the IR spectrum of poly $(\mathbf{2 c})$, a broad absorption peak characteristic of hydroxy group is observed at $3396 \mathrm{~cm}^{-1}$, and the bands at 918 and $780 \mathrm{~cm}^{-1}$ indicative of the presence of siloxy group in poly(1c) have disappeared.

\section{Thermal Stability of the Polymers}

The thermal stability of the polymers was examined by means of TGA in air (Figure 2). The onset temperatures of weight loss $\left(T_{0}\right)$ of $\operatorname{poly}(\mathbf{1 a}), \operatorname{poly}(\mathbf{1} \mathbf{c})$, poly $(\mathbf{1 e})$, and poly $(\mathbf{2 c})$ were all approximately $340^{\circ} \mathrm{C}$, indicating the considerably high thermal stability. When siloxy-containing poly(1c) was heated above $650^{\circ} \mathrm{C}$, silica $\left(\mathrm{SiO}_{2}\right)$ remained as residual ash, whose amount agreed with the value expected from the con-

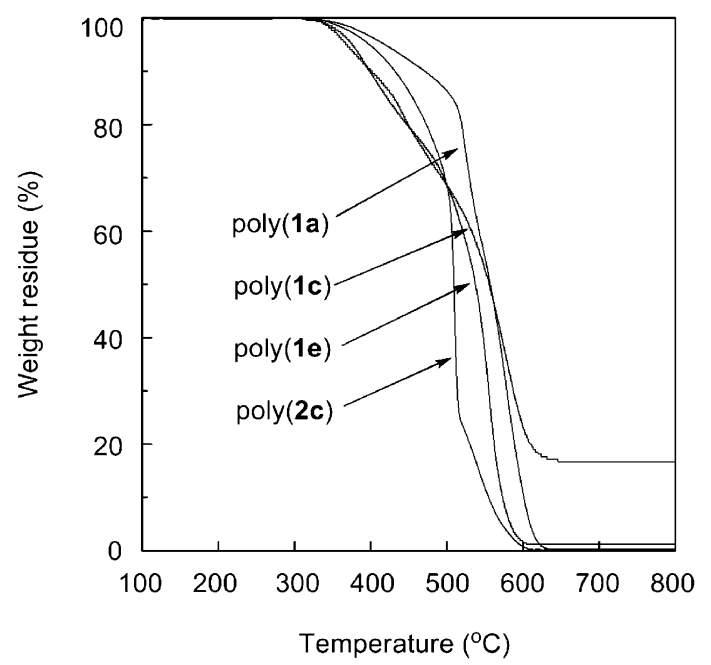

Figure 2. TGA curves of the polymers [in air, heating rate $10^{\circ} \mathrm{C} / \mathrm{min}$; $\operatorname{poly}(\mathbf{1 c})$ from run 4 , Table I; poly $(1 \mathbf{e})$ from run 4 , Table II].

Table III. Density and FFV of polymer membranes

\begin{tabular}{lccc}
\hline Membrane & $v_{\mathrm{w}}{ }^{\mathrm{a}}\left(\mathrm{cm}^{3} / \mathrm{mol}\right)$ & Density $^{\mathrm{b}}\left(\mathrm{g} / \mathrm{cm}^{3}\right)$ & $\mathrm{FFV}^{\mathrm{c}}$ \\
\hline $\operatorname{poly}(\mathbf{1 a})$ & 156.0 & 1.01 & 0.213 \\
$\operatorname{poly}(\mathbf{1 c})$ & 234.5 & 1.04 & 0.188 \\
$\operatorname{poly}(\mathbf{1})$ & 191.2 & 0.993 & 0.200 \\
$\operatorname{poly}(\mathbf{2 c})$ & 185.2 & 1.23 & 0.174 \\
$\operatorname{poly}(\mathbf{2})$ & 107.2 & 1.22 & 0.125 \\
\hline
\end{tabular}

${ }^{\mathrm{a}} v_{\mathrm{w}}$ : van der Waals volume. ${ }^{\mathrm{b}}$ Determined by hydrostatic weighing. ${ }^{\mathrm{c}} \mathrm{FFV}$ : fractional free volume, estimated from membrane densities.

tent of silicon in the polymer. In the case of desilylated polymer, poly(2c), no $\mathrm{SiO}_{2}$ residue was detected, which confirms that the desilylation proceeded quantitatively.

\section{Density and FFV of Polymer Membranes}

Table III lists the van der Waals volumes $\left(v_{\mathrm{w}}\right)$, densities $(\rho)$, and fractional free volumes (FFV) of polymer membranes. The FFV of poly(1a) was 0.213, which was lower than that of poly(PTMSDPA) $(0.24)^{31}$ and higher than that of poly[1-( $p$-triisopropylsilylphenyl)-2-phenylacetylene] (0.17). ${ }^{32}$ This indicates that the structure of the substituents has a significant effect on the FFVs of polymers, and consequently, affects the gas permeability of the polymer membranes. The FFV of $\operatorname{poly}(\mathbf{1 c})$ was 0.188 , which was lower than that of non-cyclohexyl counterpart, poly[1-( $p$-tert-butyldimethylsiloxyphenyl)-2-phenylacetylene] poly(1) (0.200). Desilylation led to the decrease of FFV of the membrane. Interestingly, desilylated membrane poly(2c) exhibited larger FFV $(0.174)$ than that of poly(2) (0.125). This is explicable 
Table IV. Gas permeability coefficients $(P)^{\mathrm{a}}$ of polymer membranes

\begin{tabular}{|c|c|c|c|c|c|c|c|c|c|}
\hline \multirow[b]{2}{*}{ Polymer } & \multicolumn{6}{|c|}{$P$ (barrer) } & \multirow[b]{2}{*}{$P_{\mathrm{O}_{2}} / P_{\mathrm{N}_{2}}$} & \multirow[b]{2}{*}{$P_{\mathrm{CO}_{2}} / P_{\mathrm{N}_{2}}$} & \multirow[b]{2}{*}{$P_{\mathrm{CO}_{2}} / P_{\mathrm{CH}_{4}}$} \\
\hline & $\mathrm{He}$ & $\mathrm{H}_{2}$ & $\mathrm{O}_{2}$ & $\mathrm{~N}_{2}$ & $\mathrm{CO}_{2}$ & $\mathrm{CH}_{4}$ & & & \\
\hline $\operatorname{poly}(\mathbf{1 a})$ & 280 & 610 & 230 & 83 & 1270 & 240 & 2.8 & 15 & 5.3 \\
\hline poly $(1 \mathrm{c})^{\mathrm{b}}$ & 110 & 180 & 70 & 20 & 370 & 60 & 3.5 & 19 & 6.1 \\
\hline $\operatorname{poly}(\mathbf{1})^{\mathrm{c}}$ & 170 & 330 & 160 & 50 & 810 & 160 & 3.2 & 16 & 5.1 \\
\hline $\operatorname{poly}(\mathbf{2 c})$ & 55 & 95 & 17 & 4.0 & 120 & 5.7 & 4.3 & 30 & 21 \\
\hline $\operatorname{poly}(2)^{\mathrm{c}}$ & 38 & 56 & 8.0 & 2.4 & 110 & 2.3 & 3.3 & 46 & 48 \\
\hline
\end{tabular}

${ }^{\mathrm{a}}$ At $25^{\circ} \mathrm{C}$ in the units of $1 \times 10^{-10} \mathrm{~cm}^{3}(\mathrm{STP}) \mathrm{cm} /\left(\mathrm{cm}^{2}\right)(\mathrm{s})(\mathrm{cmHg})(=1$ barrer$) .{ }^{\mathrm{b}}$ Sample from run 4 , Table I. ${ }^{\mathrm{c}}$ Data from reference 22

by the idea that the intersegmental packing is inhibited by the presence of bulky cyclohexyl groups.

\section{Gas Permeability of the Membranes}

Table IV lists the permeability of poly(1a), poly(1c), and poly(2c) to various gases measured at $25^{\circ} \mathrm{C}$, along with the data of $\operatorname{poly}(\mathbf{1})$ and $\operatorname{poly}(\mathbf{2})$ for comparison. The oxygen permeability coefficient $\left(P_{\mathrm{O}_{2}}\right)$ of poly $(\mathbf{1 a})$ having bulky and flexible cylohexyl groups was 230 barrers, which was much lower than that of poly(PTMSDPA) $\left(P_{\mathrm{O}_{2}}=1100\right.$ barrers). However, this value is higher than that of poly[1-phenyl2-( $p$ - $n$-butyl)phenylacetylene] having a flexible $n$ butyl substituents $\left(P_{\mathrm{O}_{2}}=100\right.$ barrers $),{ }^{33}$ indicating that the bulkiness, shape, and mobility of the substituents have a significant effect on the gas permeability of substituted polyacetylenes. The $P_{\mathrm{O}_{2}}$ value of poly(1c) was 70 barrers, which is lower than that of unsubstituted poly(1) $\left(P_{\mathrm{O}_{2}}=160\right.$ barrers). Meanwhile, the $P_{\mathrm{O}_{2}}$ value of poly $(2 \mathrm{c})$ was 17 barrers, which is twice as large as that of poly $(2)\left(P_{\mathrm{O}_{2}}=8.0\right.$ barrers $)$. This is consistent with the FFV results.

The separation factors of $\mathrm{CO}_{2} / \mathrm{N}_{2}\left(P_{\mathrm{CO}_{2}} / P_{\mathrm{N}_{2}}\right)$ and $\mathrm{CO}_{2} / \mathrm{CH}_{4}\left(P_{\mathrm{CO}_{2}} / P_{\mathrm{CH}_{4}}\right)$ of the present membranes were in the ranges of 15-30 and 5.3-21, and they tended to decrease with increase of the $P_{\mathrm{CO}_{2}}$. These results agree with the general tendency for gas permeation through polymer membranes. Upon desilylation, $P_{\mathrm{CO}_{2}} / P_{\mathrm{N}_{2}}$ and $P_{\mathrm{CO}_{2}} / P_{\mathrm{CH}_{4}}$ significantly increased from 19 and 6.1 to 30 and 21, respectively. It is clear from Figure 3 that the point of poly $(2 \mathrm{c})$ in the $P_{\mathrm{CO}_{2}}$ versus $P_{\mathrm{CO}_{2}} / P_{\mathrm{CH}_{4}}$ is located above the Robeson's upper bound. ${ }^{34}$

The gas permeability coefficients $(P)$ of $\operatorname{poly}(\mathbf{1 c})$ and poly(2c) were inspected in more detail by determining the gas diffusion coefficients $(D)$ and gas solubility coefficients $(S)$. The calculation method has been explained in the experimental section. The $D$ and $S$ of poly $(\mathbf{1 c})$ and poly $(\mathbf{2 c})$ are plotted in Figures 4 and 5 , respectively. The $D$ values of poly $(\mathbf{2 c})$ for the gases were much lower than those of poly(1c). The decrease of $D$ can be accounted for by the decrease of FFV upon desilylation. The $S$ values except $\mathrm{CO}_{2}$

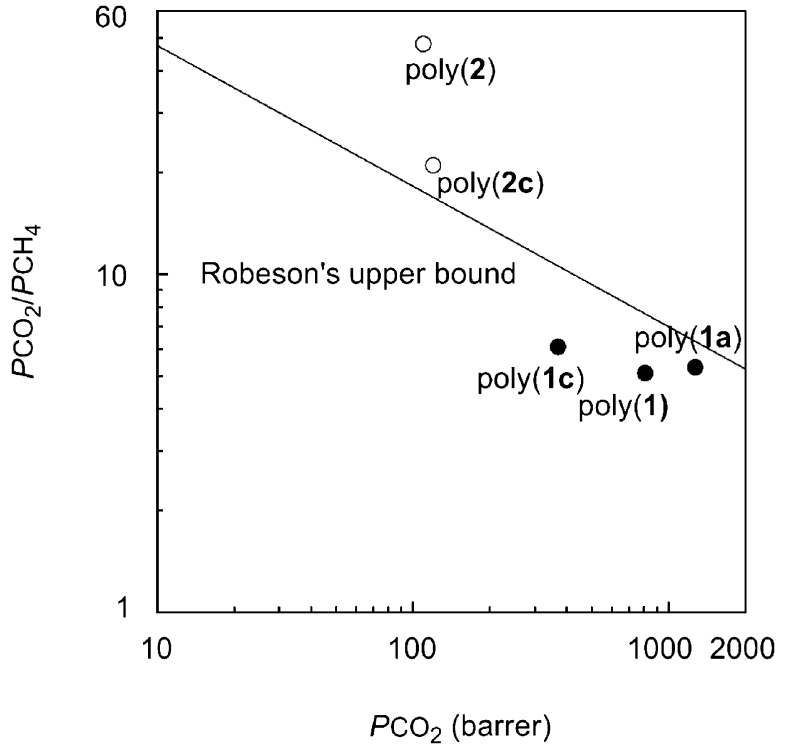

Figure 3. Relationship between the $\mathrm{CO}_{2} / \mathrm{CH}_{4}$ permselectivity and $\mathrm{CO}_{2}$ permeability of the membranes.

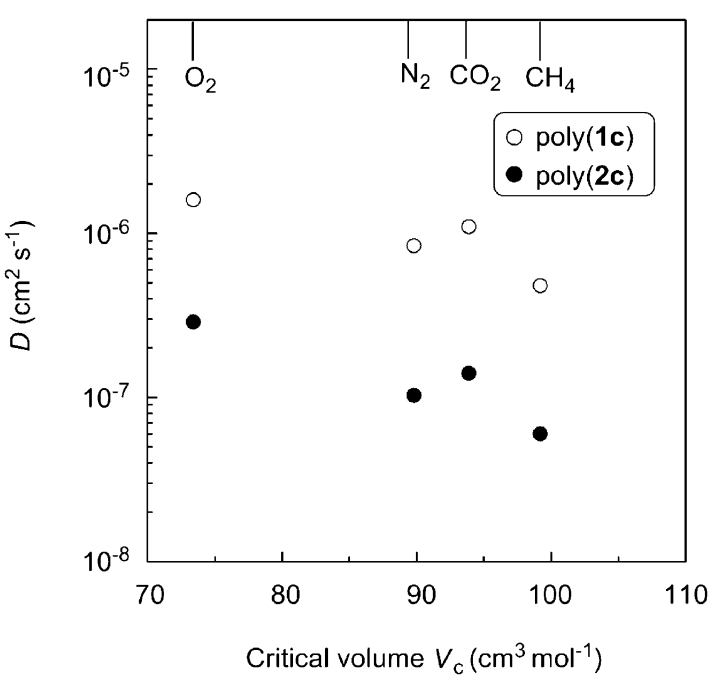

Figure 4. Diffusion coefficients $(D)$ of $\operatorname{poly}(\mathbf{1 c})$ and $\operatorname{poly}(\mathbf{2 c})$ for various gases.

hardly changed upon desilylation. The obvious increase of $S$ of poly(2c) for $\mathrm{CO}_{2}$ is attributable to the affinity of polar hydroxy groups in poly $(\mathbf{2 c})$ to $\mathrm{CO}_{2}$. 


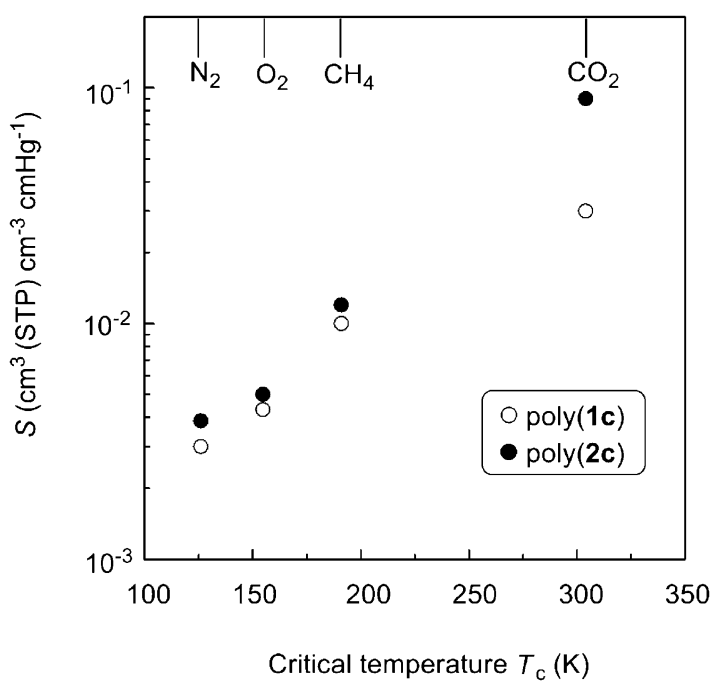

Figure 5. Solubility coefficients $(S)$ of $\operatorname{poly}(\mathbf{1 c})$ and $\operatorname{poly}(\mathbf{2 c})$ for various gases.

\section{REFERENCES}

1. T. Masuda, J. Polym. Sci., Part A: Polym. Chem., 45, 165 (2007).

2. T. Masuda, F. Sanda, and M. Shiotsuki, in "Comprehensive Organometallic Chemistry III," 1st ed, Vol. 11, Chapter 11, 16, D. Michael, P. Mingos, and R. H. Crabtree, Ed., Elsevier, Amsterdam, Tokyo, 2007, p 557.

3. T. Aoki, T. Kaneko, and M. Teraguchi, Polymer, 47, 4867 (2006).

4. J. W. Y. Lam and B. Z. Tang, Acc. Chem. Res., 38, 745 (2005).

5. R. Nomura and T. Masuda, in "Encyclopedia of Polymer Science and Technology," Vol. 1A, J. I. Kroshwitz, Ed., Wiley, 2003, p 1.

6. T. Masuda and F. Sanda, in "Handbook of Metathesis," Vol. 3, R. H. Grubbs, Ed., Wiley-VCH, Weinheim, 2003. Chapter 3, p 11.

7. K. Nagai, T. Masuda, T. Nakagawa, B. D. Freeman, and I. Pinnau, Prog. Polym. Sci., 26, 721 (2001).

8. S. K. Choi, Y. S. Gal, S. H. Jin, and H. K. Kim, Chem. Rev., 100, 1645 (2000).

9. T. Masuda, E. Isobe, T. Higashimura, and K. Takada, J. Am. Chem. Soc., 105, 7473 (1983).

10. T. Masuda, E. Isobe, and T. Higashimura, Macromolecules, 18, 841 (1985).

11. K. Tsuchihara, T. Masuda, and T. Higashimura, J. Am. Chem. Soc., 113, 8548 (1991).

12. K. Tsuchihara, T. Masuda, and T. Higashimura, Macro- molecules, 25, 5816 (1992).

13. A. P. Contreras, M. A. Tlenkopatchev, M. del Mar LopezGonzalez, and E. Riande, Macromolecules, 35, 4677 (2002).

14. G. Maier, M. Wolf, M. Bleha, and Z. Pientka, J. Membr. Sci., 143, 115 (1998).

15. D. P. Dworak, H. Lin, B. D. Freeman, and M. D. Soucek, J. Appl. Polym. Sci., 102, 2343 (2006).

16. C. H. Ting and C. S. Hsu, Jpn. J. Appl. Phys., 40, 5342 (2001).

17. S.-Y. Oh, R. Ezaki, K. Akagi, and H. Shirakawa, J. Polym. Sci., Part A: Polym. Chem., 31, 2977 (1993).

18. H. Suzuki, K. Nakamura, and R. Goto, Bull. Chem. Soc. Jpn., 39, 128 (1966).

19. E. Yashima, S. Huang, T. Matsushima, and Y. Okamoto, Macromolecules, 28, 4184 (1995).

20. K. Sonogashira, J. Organomet. Chem., 635, 46 (2002).

21. T. Suzuki, E. Sato, K. Unno, and T. Kametani, J. Chem. Soc., Perkin. Trans. 1, 2263 (1986).

22. Y. Shida, T. Sakaguchi, M. Shiotsuki, F. Sanda, B. D. Freeman, and T. Masuda, Macromolecules, 39, 569 (2006).

23. H. Lin and B. D. Freeman, J. Membr. Sci., 239, 105 (2004).

24. M. R. Pixton and D. R. Paul, in "Polymeric Gas Separation Membranes,” D. R. Paul and Y. P. Yampolskii, Ed., CRC Press, Boca Raton, FL, 1994, p 83.

25. D. W. van Krevelen, in "Properties of Polymers: Their Correlation with Chemical Structure; Their Numerical Estimation and Prediction from Additive Group Contributions," 3rd ed., Elsevier Science, Amsterdam, 1990, p 71.

26. A. Bondi, in "Physical Properties of Molecular Crystals, Liquids, and Glasses," R. F. Boyer, Ed., John Wiley and Sons, New York, 1968, p 25.

27. T. Masuda and H. Tachimori, J. Macromol. Sci., Pure Appl. Chem., 31, 1675 (1994).

28. T. Masuda, M. Teraguchi, and R. Nomura, in "Polymer Membranes for Gas and Vapor Separation," ACS symposium series 733, B. D. Freeman and I. Pinnau, Ed., American Chemical Society, Washington, 1999, p 28.

29. T. Masuda, M. Yamagata, and T. Higashimura, Macromolecules, 17, 126 (1984).

30. T. Masuda, T. Yoshimura, K. Tamura, and T. Higashimura, Macromolecules, 20, 1734 (1987).

31. X.-Y. Wang, R. D. Raharjo, H. J. Lee, Y. Liu, B. D. Freeman, and I. C. Sanchez, J. Phys. Chem. B, 110, 12666 (2006).

32. K. Nagai, L. G. Toy, B. D. Freeman, M. Teraguchi, T. Masuda, and I. Pinnau, J. Polym. Sci., Part B: Polym. Phys., 38, 1474 (2000).

33. H. Kouzai, T. Masuda, and T. Higashimura, J. Polym. Sci., Part A: Polym. Chem., 32, 2523 (1994).

34. L. M. Robeson, J. Membr. Sci., 62, 165 (1991). 